\title{
An Investigation of the Impact of Manipulation of Task Complexity on Cognitive Processes Into Both NS and Second Language Learners
}

\author{
Adnan Mukhrib \\ Department of English Language, Yanbu University College, Saudi Arabia
}

\begin{abstract}
This study takes as its basis a recognition that task-based learning is now recognized as having major benefits in promoting L2 learning, and how cognitive load affects speech production. In addition, there has been a recent examination of the impact of task complexity, real-world meaning, and the overall cognitive load needed to be expended by students. Different task types have been evaluated in terms of how they improve aspects of language. However, less consideration has been given to the effect on the cognitive load of different task types with the speech production processes (conceptualization, input, output identification, monitoring, and reformulations). Drawing on data collected from 112 participants (56 Native Speakers, 56 Non-Native Speakers) who completed a series of tests of varying complexity and were asked to evaluate on a rating scale, the level of mental effort expended. The results indicated that complexity increases mental effort and thus cognitive load, and that conceptualization appears to be one area where greater effort is required before being able to problems solving. Formulation comments suggest that there was a high level of hesitation, self-checking, and assessment as the level of task complexity increased. The implications for teaching and syllabus design are also considered.
\end{abstract}

Index Terms — task-based learning, cognitive load, task complexity, speech production processes

\section{INTRODUCTION AND BACKGROUND}

In today's developing multicultural society, learners of a foreign language do so to be able to apply the knowledge in everyday life (for example, work, study, holidays, or other aspects). Thus, the idea of teaching a foreign language has developed into a process that learning should not be through exercises, but through relevant, meaningful tasks. In this context, a significant volume of work has focused on teaching through task-based activities (Ellis, 2003; Doughty and Long, 2003), where pedagogical tasks are tightly related to some activities from daily routines and presented as goaloriented real-life activity (Skehan 1998). Although these tasks seek to get as close as possible to reality, they are still elaborated for a classroom context, which requires some issues to be taken into account.

Included in prior research in this area is the issue of task complexity and how it impacts cognitive processes such as output, fluency, and accuracy for both L2 learners and native speakers (Moattarian et al, 2019). Indeed, several authors have manipulated and analyzed different types of tasks to see how they work with L2 speech production (Gilabert, 2007; Kuiken \& Vedder, 2007; Ortega, 2001). On the other hand, many studies have affirmed the necessity of research in the use of tasks in L2 acquisition (Skehan \& Foster, 2001; Robinson, 2007; Gilabert 2007). A series of unsolved problems have been identified, such as what kind of tasks teachers should choose, how they should organize them throughout the sessions, and importantly, how to analyze learners' progress. Thus, having admitted the need for further research into several aspects of tasks, the focus of this study will be concentrated on cognitive load and processes used in task completion, based on increasing levels of complexity. What this means is the analysis of the impact of cognitive tasks of complexity during task-based pedagogy. The use of activity-based or pedagogic tasks to encourage learning is not a new concept and indeed has been widely used in a range of teaching settings. The view is that student-centred active learning is encouraged and supported by engaging learners with tasks that focus their attention on the subject at hand.

Several studies recognise how task-based learning is more effective than the more traditional, passive, and rote learning that was the cornerstone of language learning for many years (Ellis, 2006; Shehadeh \& Coombe, 2012; Pica, 2013). This suggests that language processes are supported by the use of tasks and that this in turn leads to gains in proficiency. Furthermore, evidence suggests that when learners become engaged with the process, their learning and cognitive development of understanding of the language is improved, along with their confidence and motivation (Willis, 1996; Littlewood, 2004; Viriya, 2018). At the same time, there has also been consideration of which types of tasks are more effective for achieving this desired competence and level of learning (see Van Avermaet \& Gysen., 2006; Harwood, 2010; Schmidt, 2012). However, there is a lack of empirical work in the area of understanding the different elements of cognition and knowledge that may be utilized during the completion of the task. Speech production processes such as conceptualization and formulation, attention to input, output, and the depth of processing that is undertaken may all be influenced by the complexity of a task (Shehadeh, 2005; Ong \& Zhang, 2013). Some researchers have taken a few steps within the area of task sequencing by forwarding principles for organizing tasks from the simple 
to difficult in a syllabus (Breen, 1984; Prahbu, 1987). These early studies used the cognitive complexity of tasks as a reference, and they suggested that tasks should be manipulated in terms of $+/$ - abstractness; +/- few elements; +/reasoning, among others, but none of those approaches advanced a model to justify task distribution and organization along with a series of sessions.

The current study is, therefore, aimed at examining the cognitive load and processes used in task completion, based on increasing levels of complexity. What this meant in more specific terms was an examination of how manipulation of task complexity affects cognitive processes in the output, fluency, and accuracy of both Native Speakers (NS) and second language learners, or non-native speakers (NNS). In other words, this study aims to develop a foundation for a new study that examines the impact of manipulation of task complexity on the cognitive procedures of L2 learners. In this way it was anticipated that new information may come to light, highlighting new areas for research which would lead to the development of a methodological approach to examine the effect of task complexity in greater detail.

\section{Pedagogical TASK AND TAsk CompleXity}

A core facet of the work is to understand what is meant in the SLA sector by pedagogic tasks. The simplest definition is that pedagogic tasks are activities, which, as Willis (1996) indicates, can be real-world based. Real-world tasks are those may occur every day because as individuals, for example, can describe a problem to a doctor, narrate a story from pictures, write letters for university or apply for a job. In the classroom setting, tasks are more frequently gap fill, problem-solving, or mapping. One definition is that the tasks are performed that students may not do outside of a classroom, such as filling in blanks, or completing a dialogue (Viriya, 2018). However, there is a growing recognition of the value of completing real-world tasks such as writing a letter, narrating a story, or evaluating a dialogue, so that the task has meaning, context, and relevance for the students (Ozverir et al, 2017).

In other words, in SLA context, a task should involve the learner's first understanding of what they are required to do, and the goal that is to be achieved as well as the language to be used, then through manipulation, production and reformulations identify the language and grammatical features necessary to complete the set task (Viriya, 2018). At a cognitive level, this means that students have to access their existing linguistic knowledge, both lexical and grammatical, potentially discuss and negotiate meaning and form with partners, and then use this information to complete the set task and its level of complexity (Ozverir et al, 2017; Ellis, 2006).

In brief, task complexity refers to the inherent cognitive demands of a given task. In other words, how much consideration and thought (working memory) must be given over to complete the task (Shajeri \& Izadpanah, 2016). These components can include increases in elements, (different grammatical structures/semantics or parts of a task), increased reasoning - for example determining what the task involves and how many stages, and also whether the task requires completion of one element (the language to be used) before completing a second or third (creating a narrative from pictures for example). Robinson (2007) suggested that the most effective way to develop viable tasks is to consider the level of intentional memory, reasoning, and information processing demands of the proposed task. Certainly, this appears to be a valid view but does not necessarily take into account the type of task and the range of cognitive demands required for each element.

However, an agreement has been reached with the idea that empirical studies need to provide more evidence regarding the role of task sequencing (Robinson, 2001, 2007, 2011; Skehan \& Foster, 2001; Gilabert, 2005). To our knowledge, only one model of task sequencing has been proposed (Robinson, 2005), in which a detailed theoretical background for further empirical studies on task sequencing based on the Cognition Hypothesis has been advanced which is described below.

\section{THEORETICAL FRAMEWORK}

\section{A. Trade-Off Hypothesis}

Skehan $(1996,1998)$ suggests that the development of tasks should be focused on recognizing that learners' attention may be divided, in essence, that the task demands should not create a mental load that reduces the ability to create a response in L2. From a mental load perspective, the learners should still have resources available which can be focused on the form of the language required. Van Patten (1990) supports Skehan, indicating that learners have limited resources for attention if they have to divide their attention between task demands and language forms, leading to a reduction in either meaning or fluency. In essence, tasks that are considered, from the perspective of the individual student to be too complex, will lead to sacrificing either fluency or accuracy, or sometimes both to meet the demands of a task. Moreover, Skehan and Foster (2001) suggest that when a task is perceived as complex, learners realize that simple language will not provide the required answer, but that this does not necessarily mean that they will attempt to use more complex language.

Skehan's (2001) perspective is that a learner will give priority to one aspect of language, for example meaning rather than form, even though they may not identify the impact of instruction processes or the drawing of attention to specific forms. Skehan argues that learners will give focus to pre-task planning and notes how this can draw attention to a focus on form, based on the view that a student will have a natural orientation to form as opposed to meaning or put another way to complexity over accuracy. For Skehan, the pre-task planning stage is important because the student will then be 
able to conceptualize internally what they plan to say, which requires access to grammatical or lexical features. Therefore, the basis of the trade-off is during planning rather than speaking. The challenge with this hypothesis is that the trade-off has not been tested empirically and does not take into account the cognitive load under which students work. Despite this potential shortcoming, the notion of a trade-off, whether during planning or utterance, does have an impact on how to manipulate task complexity and where and how complex tasks should be placed into a syllabus.

Previous studies (Jong, 2009; Gass and Mackey, 2007) have affirmed that there may be a greater effect from the task type and how the task itself can "push" output from the learner. The pushing leads to stretching of knowledge through negotiation of meaning and attention to the form of the words they are using, which, according to Swain (1985) may occur during planning or utterance. In essence, the output provides an opportunity for learners to notice gaps in knowledge, test and reflect on knowledge, and receive feedback, offering learning moments. In other words, pushing students to produce an output through the requirements of a task moves the learner from semantic to syntactic processing according to Swain (1985). Nation \& Newton (2009) confirmed this view, taking the stance that comprehension is the coding of semantics to enable the production of syntax. Nation (2011) also advocated for learners to undertake tasks of varying complexity to enable them to focus on where there are gaps, but also to become aware of the trade-off between complexity and accuracy.

This distinction may be important in understanding task manipulation and its effect on accuracy as tasks can be either simple with one goal, or more complex with multiple steps. In the view of Archard and Niemeir (2004), pushing for output supports learners' identification of a conscious noticing of gaps in their intended versus their actual output. In other words, they notice a gap, have a greater focus on their form and meaning and ultimately there is an improvement in their language skills. This noticing and focus however do have a corresponding impact on the cognitive load under which the student will work. Recognition of this impact led to the development of the cognition hypothesis (Robinson, 2001).

\section{B. Cognition Hypothesis}

Cognitive load is defined as how much working memory uses to complete a task or carry out an action (Abeysekera \& Dawson, 2015). Based on the Cognition Hypothesis, pedagogical tasks should be organized by gradually increasing cognitive complexity through different types of cognitively affecting variables (Robinson, 2001). According to cognitive load theory, there are three types: extraneous, intrinsic, and germane. The first of these is grounded in the presentation of the task, i.e. the mode of instruction, the second to the effort necessary to complete the task and the third is how much effort is required to create lasting knowledge (Kalyuga, 2011). In the context of task-based learning, therefore, these three elements refer to the type of task (written, oral, group, or individual for example), the complexity of the task, and finally how likely the task and its completion is to lead to improvement in language learning (Haidet et al, 2014).

It is important to remember that information will only be stored in long-term memory. What this means is that there is a creation of a schema or the germane stage after working memory has dealt with the issue or task. The challenge for L2 learners is that working memory is limited in capacity. When the limits of this capacity have been reached, due to the complexity of a task, or an excess of unfamiliar language, the task may be perceived as challenging (Liao, 2019).

Therefore, the level of cognitive load is crucial for task completion. Robinson's (2001) view was that increasing cognitive load can have a negative effect on accuracy and complexity of response and at least an initial stage of learning, fluency. However, if there is an incremental increase in complexity over time, according to Robinson (2001, 2003, 2011), the learner is better able to manage the cognitive load, leading to a decrease in the effects on complexity and accuracy and ultimately fluency. This is likely to be important in understanding how to manipulate tasks to influence the cognitive load of learners during the task-based performance. In the case of a demanding task at the level of reasoning, for instance, a more complex task will require from the learner the use of syntactically more difficult target structures. Beyond task complexity, other components are likely to affect L2 acquisition, as postulated in some previous studies (Robinson, 2001; Spilsbury, Stankov \& Roberts, 1990). More specifically, learners' differences, which are external to a task, determined among others by working memory capacity as part of aptitude, may play an important role in $\mathrm{L} 2$ acquisition.

The result, according to Robinson (2003), is that there will be a communicative failure during the process and a failure to complete the task effectively. At the same time, and recognizing the value of interaction as a support for managing cognitive load, Robinson (2003, 2007), advised that when breakdowns occur, these incidents can be used as an opportunity to create meaningful exchanges. Through negotiation, clarification, and exploration to identify the correct form and thus meaning for the interlocutor, the cognitive load is better managed. The challenge for students however is being able to manage the cognitive load necessary to undertake this type of negotiation. In the case of beginners, and potentially some intermediate students, there may be difficulties in identifying at a semantic, lexical, or grammatical level, the appropriate language to negotiate meaning and form during tasks. This again will be dependent on the complexity and other cognitive loads of the task.

From the examination of existing perspectives, it is indicated that task complexity can be used to explain what features of a task can be manipulated to either raise or lower the overall task demands. What this means is that there is a potential that manipulating the demands of a task can be aligned with learner ability (Robinson, 2007). In a task-based learning setting, this leads to the view that understanding which aspects of a task need to be manipulated for the 
optimum cognitive load (a balance between stretching the student but not pushing them so far that there is communication failure) may be a vital area of research for the future. It is also likely to be the case that manipulating tasks to adjust for the cognitive load can allow for the introduction of real-world tasks that begin simply and increase over time as the learners' knowledge and ability to negotiate learning opportunities increases.

Undeniably, there has been a study undertaken into the relationship between the tradeoff between output and complexity by both Robinson (2001, 2003, 2007) and Skehan and Foster (2001). These have included assessment of different task types, related to length, complexity, and content, and Robinson (2001) identified that complexity can be assessed through both familiarity with the task (and language used) and the number of elements or parts of a task. From the cognitive perspective, it would appear that if sequencing, difficulty, and production complexity can be manipulated, combined with student familiarity of the task, then the cognitive load can be assessed. Several studies have examined Robinson's perspective regarding the effect of complexity on cognitive load, for example, Ishikawa, (2007) and Kuiken and Vedder, (2007). Ishikawa's work identified that both complexity and accuracy were highly affected at a significant level for complex tasks. This supports Robinson's view that accuracy is negatively impacted by increased complexity.

It is however interesting to note that Skehan (1998) and Foster and Skehan (2001) suggested that it is not the task complexity that is the issue, but attentional issues with task completion. In their view, the cognitive load necessary to pay attention to the complexity of a task takes precedence over the working memory load for accuracy. This appears, according to Robinson (2001), that the focus for Skehan is on attention, rather than task complexity, suggesting that if attentional capacity could be increased, for example through motivation and meaningful tasks, the effect of complexity on accuracy would be reduced.

From the evaluation of these theoretical frameworks, it is apparent that the adoption of task-based learning can be highly beneficial, partially due to the interaction that can be encouraged between peers, and native speakers, but also due to the stretching of the learners' knowledge through collaboration, exploration, and clarification as they notice gaps in their knowledge, meaning that the trade-off between complexity and accuracy may become smaller. At the same time, it is also evident that there may be an impact from task complexity on the overall cognitive load of the student, and thus their ability to manage the task.

Previous research has considered a range of elements including L2 production, and L2 development in the context of task complexity, (Gilabert, 2007; Révész, 2011) which aimed to test the relationship between task complexity, accuracy, and/or fluency. The results have shown some variation for the cognition hypothesis, although this work was focused on L2 writing, which may lead to different cognitive processes than those required for L2 speech production. Furthermore, Révész (2011) found that as the complexity of tasks increased, there was a corresponding drop in syntactic complexity but increased lexical diversity. These studies appear to suggest that the cognitive load approach needs more in-depth testing and evaluation, as there is an effect, but that it is variable depending on mediating factors such as group interaction, and the needs of the task in terms of syntactic, semantic or lexical requirements.

Given that cognition models have focused on L2 production and development and the use of working memory models such as that of Baddeley (2003), it appears that, in the context of the cognition hypothesis, consideration should be given to examining increased task complexity along dimensions that direct resources to the expenditure of greater effort from students in terms of conceptualization, formulation, attention to input and output and depth of processing, subject to individual differences in students proficiency and understanding. All of this leads to identification of a research gap.

\section{Research Aims and Questions}

Initial investigation of existing research has identified that there is a relationship between the independent variable of task complexity and the dependent variables of L2 speech production and L2 development. Although frameworks exist, the constructs within these have not been given sufficient attention to each construct within the framework. As a result, whilst there is a recognition of the relationship between task complexity and L2 production and development, this has not fully considered how cognitive processes can be used to explain the relationship. In other words, speech production processes such as conceptualization, formulation, attention to input /output, and depth of processing have been underexplored. The present study, therefore, will seek to fill this gap in empirical studies.

The primary question to be asked is what effect do task complexity and manipulation have on cognitive processes for speech production for NS and second language learners?

1. What impact does manipulation of task complexity for narrative tasks have on speech production processes?

2. What impact does manipulation of task complexity for mapping tasks have on the speech production processes?

3. What impact does manipulation of task complexity for problem-solving tasks have on speech processes?

\section{METHODOLOGY}

From the evaluation of existing literature and prior works in assessing complexity and how this affects speech production, the question then arises as to which is the most effective means of tapping these various explanatory processes and examining their relationship to task complexity and ultimately L2 outcomes. One solution is to use the triangulation mixed-methods approach. This approach requires the collection, analysis, integration, and sharing both quantitative and qualitative data in either single or multiphase studies so that there is a double level of validity and 
reliability in both the results and how they are interpreted. As part of the process, self-ratings on the effort expended during a range of complex tasks were utilized to provide the quantitative data, whilst the qualitative data came from evaluation by the participants following the stimulated response and stimulated recall elements of the experimental stage.

\section{A. Participants}

Data were collected from 112 participants who all participated voluntarily in the study. 56 students were native English speakers (NS), and 56 were non-native speakers (NNS), who were Saudi university learners of English. Their mean age was 23 . They were undergraduate students majoring in mechanical engineering. The NNS were assessed for proficiency levels using the Oxford Placement test and graded as being at level B1 to B2 CEFR. In terms of tasks, the participants completed the following tests, details of which can be found in the appendices.

\section{B. Tasks and Procedures}

Task 1 - Narrative

Students were asked to provide a short narrative about their grandparents but with a focused goal, such as the jobs their grandparents had undertaken. This allowed for longer narratives and potentially the use of greater shared interaction and checking of input/output. The exercise was assessed using the rating scales shown below and was a selfmarked rating, as adopted by Gilabert et al, (2009).

Task 2: Mapping Exercise

Students were given some key vocabulary relating to giving directions, but with the adoption of a dual methodology approach. In other words, a secondary task was required to be undertaken alongside the primary task. Following the route of Cierniak et al, (2009), a visual stimulus was utilized. This involved changing the background colour of pictures on the computer screen to red and green, with students asked to respond to pictures with green backgrounds only, even though the screens retained the original questions - the primary task. Accuracy, measured in terms of counting lexical, syntactical, and phonological errors and converting these to an accuracy percentage of the overall output was counted along with eye fixations.

Task 3 - Problem Solving Task

The cohort was asked to imagine they lived in a town centre where there was a major problem with traffic. They were asked to discuss the problems and identify solutions, before deciding which would be the cheapest, which would be the most innovative, and environmentally friendly. Each solution should have both advantages and disadvantages identified in the response. Again, the students were asked to utilize the self-ratings scale on the complexity of the task. The purpose of adopting dual-task methodology was that the task was more complex than the first simple narrative, but also the recognition that the performance on the secondary task (i.e. responses to red/green) can be assessed for reaction time and is likely to mirror the level of cognitive load required to achieve the primary goal of the task (the directions) as indicated by Cierniak et al, (2009).

\section{Data Analysis}

The data for analysis was gathered using a range of measures:

a) A self-completed rating scale

b) Eye Tracking

c) Stimulated recall

\section{A. Task Rating Scale}

The scale for assessment of the task complexity (please see figure 2 in the appendices) was used for self-assessment by all participants of the complexity of the task and led to the quantitative results. Students were also asked to give their subjective time estimation on the length of time they believed it had taken them to complete the task. This element was included as following Block et al (2010), the estimated time for completion increases in line with the perceived complexity of a task. From this rating scale, quantitative data emerged.

\section{B. Eye Tracking}

Eye-tracking as a measure can be achieved through either identification of moment-by-moment eye fixations when a participant is interacting with a visual stimulus, with the measure being either the number or duration of fixations which provides information about how a participant may allocate cognitive resources to attention (Zhai et al, 2018). Heat maps can also be used, which identify gaze duration for different stimuli, for example, whether the background of dualtask is red or green. Gaze plots are also potentially beneficial as they show the sequence or path of a participant's eye movements/fixations (Holmqvist et al, 2011). In the current study, the measure selected was the number and duration of fixations during the mapping task only, leading to quantitative data for analysis.

\section{Simulated Recall}

This measure is an offline procedure that aims to examine the thoughts and cognitive processes by prompting responses to recall the thoughts they may have had whilst completing a task. The view is that using a visual or aural 
stimulus can create recall of the thoughts and processes. From this measure, the qualitative data was created through playing back recordings to students of their performance twice and then asking them to consider their thoughts firstly when they felt they had expended greater mental effort and secondly when the recording was stopped due to indications identified by the researcher of mental effort (pausing, self-corrections, and hesitations for example). The analysis was undertaken using Gass and Mackey (2000) and Kormos (2006) which involves coding for comments that identified conceptualization (planning) and formulation (lexical, phonological, and syntactical encoding).

\section{RESULTS}

The quantitative data was input into SPSS and analyzed and in all the tests, the self-ratings indicated that the greater the complexity of the task, the greater the mental effort they felt that they had to expend. The tables below indicate the means achieved for each of the three tests on the rating scales.

TABLE 1

MEANS For RATING SCALES On 3 TESTS

\begin{tabular}{|l|l|l|l|}
\multicolumn{4}{c|}{ MEANS FOR RATING SCALES ON 3 TESTS } \\
\hline & $\begin{array}{l}\text { Task 1 - } \\
\text { Narrative }\end{array}$ & $\begin{array}{l}\text { Task 2 } \\
\text { Mapping }\end{array}$ & $\begin{array}{l}\text { Task 3 - } \\
\text { Problem Solving }\end{array}$ \\
\hline Mental Effort & 1.813 & 6.11 & 6.58 \\
\hline Task Difficulty & 1.786 & 6.3 & 6.446 \\
\hline Task Anxiety & 1.25 & 6.3 & 6.089 \\
\hline Completion Success & 5.99 & 4.16 & 2.411 \\
\hline Interest & 6.58 & 1.99 & 7.027 \\
\hline Motivation & 6.52 & 1.25 & 6.143 \\
\hline
\end{tabular}

As Table 1 highlights, as the complexity of the tasks increased, there was a concurrent increase in perceptions of mental effort and task difficulty with no significant variation between NS and NNS. It is notable however that motivation and interest were much lower for the mapping exercise, and that the narrative task, which involved speaking about the experience, was rated highest for motivation. This underlines the importance of ensuring that tasks are designed to engage students as noted by Ozverir et al, (2017). It was also clear, that as anticipated there was a significant correlation between NNS and NS perceptions of task difficulty, illustrated in Tables 2 and 3 below.

TABLE 2

CORRELATION BETWEEN TASK DIFFICULTY AND NS/NNS

Pearson's Correlations

\begin{tabular}{llc}
\hline & & Pearson's r \\
\hline Native or NNNS & - Task 1 rating task difficulty & $0.656^{* * *}$ \\
Native or NNNS & - T2 Difficulty & 0.033 \\
Native or NNNS & - T3 Difficulty & -0.046 \\
Task 1 rating task difficulty & - T2 Difficulty & 0.015 \\
Task 1 rating task difficulty & - T3 Difficulty & 0.118 \\
T2 Difficulty & - T3 Difficulty & -0.167 \\
& & \\
\hline
\end{tabular}

Note. All tests one-tailed, for a positive correlation

$* \mathrm{p}<.05, * * \mathrm{p}<.01, * * * \mathrm{p}<.001$, one-tailed

TABLE 3

DESCRIPTIVE STATISTICS

\begin{tabular}{|l|l|l|l|l|l|l|}
\hline Descriptive Statistics & T1 difficulty & \multicolumn{2}{l|}{ T2 difficulty } & \multicolumn{2}{l|}{ T3 difficulty } \\
\hline & NNS & NS & NNS & NS & NNS & NS \\
\hline & 56 & 56 & 56 & 56 & 56 & 56 \\
\hline Valid & 2.357 & 1.214 & 6.357 & 6.250 & 6.375 & 6.518 \\
\hline Mean & 0.841 & 0.414 & 1.645 & 1.587 & 1.567 & 1.537 \\
\hline Std. Deviation & 1.000 & 1.000 & 4.000 & 4.000 & 4.000 & 4.000 \\
\hline Minimum & 4.000 & 2.000 & 9.000 & 9.000 & 9.000 & 9.000 \\
\hline Maximum & & & & \\
\hline
\end{tabular}

What this suggests is that the cognitive load for those familiar with the language is less, which was an anticipated outcome. However, a surprising finding, concerning mental effort, was that only task one which showed meaningful variation between the two groups (see Tables 4 and 5). 
TABLE 4

PEARSONS CORRELATION MENTAL EFFORT

$\underline{\text { Pearson's Correlations }}$

\begin{tabular}{llc}
\hline & & Pearson's r \\
\hline Native or NNNS & - T2 Mental Effort & 0.018 \\
Native or NNNS & - T3 Mental Effort & 0.006 \\
Native or NNNS & - Task 1 Rating Mental Effort & $0.625 * * *$ \\
T2 Mental Effort & - T3 Mental Effort & 0.091 \\
T2 Mental Effort & - Task 1 Rating Mental Effort & 0.105 \\
T3 Mental Effort & - Task 1 Rating Mental Effort & -0.070
\end{tabular}

Note. All tests one-tailed, for positive correlation

$* \mathrm{p}<.05, * * \mathrm{p}<.01, * * * \mathrm{p}<.001$, one-tailed

TABLE 5

DESCRIPTIVE STATISTICS

\begin{tabular}{|c|c|c|c|c|c|c|}
\hline \multicolumn{7}{|c|}{ Descriptive Statistics } \\
\hline & \multicolumn{2}{|c|}{ T1 Mental Effort } & \multicolumn{2}{|c|}{ T2 Mental Effort } & \multicolumn{2}{|c|}{ T3 Mental Effort } \\
\hline & NNS & NS & NNS & NS & NNS & NS \\
\hline Valid & 56 & 56 & 56 & 56 & 56 & 56 \\
\hline Mean & 2.357 & 1.268 & 6.143 & 6.089 & 6.589 & 6.571 \\
\hline Std. Deviation & 0.862 & 0.447 & 1.507 & 1.541 & 1.627 & 1.582 \\
\hline Minimum & 1.000 & 1.000 & 4.000 & 4.000 & 4.000 & 4.000 \\
\hline Maximum & 4.000 & 2.000 & 9.000 & 9.000 & 9.000 & 9.000 \\
\hline
\end{tabular}

However, examining the impact of anxiety on perceptions of mental effort, showed a significant correlation for the most complex task, as Tables 6 and 7 illustrate. In essence, it appears that when the participants were anxious about their ability to complete the task, their perception of mental effort increased whilst their view on completion success was reduced.

TABLE 6

MENTAL EFFORT VS ANXIETY

Independent Samples T-Test

\begin{tabular}{llccc}
\hline & Test & Statistic & df & p \\
\hline T3 Mental Effort & Student & 0.059 & 110.000 & 0.953 \\
& Welch & 0.059 & 109.916 & 0.953 \\
T3 Anxiety & Student & 0.125 & 110.000 & 0.901 \\
& Welch & 0.125 & 109.990 & 0.901 \\
T3 Completion success & Student & 0.000 & 110.000 & 1.000 \\
& Welch & 0.000 & 110.000 & 1.000 \\
\hline
\end{tabular}

TABLE 7

DESCRIPTIVE STATISTICS

\begin{tabular}{|l|c|c|c|c|c|c|}
\hline \multicolumn{9}{|c|}{ Descriptive Statistics } \\
\hline & \multicolumn{2}{|c|}{ T1 Mental Effort } & \multicolumn{2}{c|}{ T2 Mental Effort } & \multicolumn{2}{c|}{ T3 Mental Effort } \\
\hline & NNS & NS & NNS & NS & NNS & NS \\
\hline Valid & 56 & 56 & 56 & 56 & 56 & 56 \\
\hline Mean & 6.589 & 6.571 & 6.375 & 6.518 & 6.107 & 6.071 \\
\hline Std. Deviation & 1.627 & 1.582 & 1.567 & 1.537 & 1.510 & 1.524 \\
\hline Minimum & 4.000 & 4.000 & 4.000 & 4.000 & 4.000 & 4.000 \\
\hline Maximum & 9.000 & 9.000 & 9.000 & 9.000 & 9.000 & 9.000 \\
\hline
\end{tabular}

What this indicates that irrespective of L1, as a task increases with complexity, there is a corresponding perception of a need for increased mental effort and this has a correlating impact on anxiety and thus chances of effective completion. This aligns with both the trade-off and cognition hypothesis and their recognition of the need for a balance between complexity and accuracy, but also highlights the variable of individual perceptions and thus the potential impact of anxiety (Farrokhi \& Sattarpour, 2017). No variation between NNS and NS was identified for completion success, motivation, or interest, suggesting that assessment of the test requirements is not affected by whether the participant is a learner or native speaker. This would however need confirmation with future larger samples.

Concerning anxiety, however, there was a clear correlation between NS and NNS as the Anova analysis illustrates. As shown in Table 3, there is a significant (0.925) correlation between anxiety on the three test conditions and whether the participant was a native or non-native. This is not an unexpected finding as it was hypothesized that NNS would have greater anxiety over the tests, due to the double load of the task itself and the identification of the right language to be used. 
TABLE 8

ANOVA FOR ANXIETY LEVELS VS NS/NNS

\begin{tabular}{|l||r|r|r|r|r|c||}
\hline \multicolumn{1}{|l||}{ SNOVA } \\
\hline Model & Sum of Squares & df & Mean Square & F & p \\
\hline $\mathrm{H}_{1}$ & Regression & 0.122 & 3 & 0.041 & 0.158 & 0.925 \\
\hline & Residual & 27.878 & 108 & 0.258 & & \\
\hline & Total & 28.000 & 111 & & & \\
\hline
\end{tabular}

It appears therefore that the perceptions of mental load and cognitive effort have an impact on how difficult a task is believed to be. Moreover, it was further identified that as a task increases in complexity, there is an increase in the perception of difficulty and anxiety around the tests.

The quantitative findings tie in with the cognition hypothesis and the indication that there is a trade-off between the complexity of task and mental effort indicated by Robinson (2001). In addition, recent works by Malicka and Levkina (2012) and Baralt (2010) also confirm that there is an effect in terms of time estimation with regards to the perceived complexity of a task, which was confirmed by the results of this study. However, the estimations for more complex tasks were less precise, based on the tables for completion success, suggesting that the participants were less able to identify the time needed when the task demands were more complex.

In the dual-task condition, again the complex tasks were perceived as require more mental effort, indicating a perceived increase in cognitive load, with a similar outcome concerning time estimations as seen in the narrative and problem-solving tasks, as shown in the means illustrated in Table 1. This aligns with work by Lee (2019) who noted that estimations of time on task could be divided into time on planning and time on speech and thus become a viable measure of mental effort and cognitive load when completing tasks. This distinction was not identified in the rating scale for this work, but the figures for task completion success evaluation suggest that there is a need to undertake this separation of perceived time estimations. In the dual-task, the quantitative measure used was eye fixation duration, and Table 9 shows the mean eye fixations for the three conditions, measured in $\mathrm{ms}$.

TABLE 9

MEANS FOR EYE FIXATIONS

\begin{tabular}{|l|l|l|l|}
\hline \multicolumn{2}{|l|}{ Descriptive Statistics } & T2 eye fixation green & T2 eye fixation red \\
\hline Mean & T2 Average Eye Fixations plain $(\mathrm{ms})$ & T2 & 282.143 \\
\hline
\end{tabular}

As Table 3 shows, there was a longer eye fixation on the red background, suggesting that when undertaking the mapping task, a greater cognitive load was necessary to differentiate between the background colour and the demands of the task. In addition, accuracy was reduced for the red condition, due to the increased effort required to make this differentiation. There was no major variation between the NS and NNS participants for this test, with both groups having longer eye fixation on the red. This is in line with Cierniak et al, (2009) and their recognition of the effect of the split-attention factor affecting cognitive load and ultimately accuracy. Accuracy was also affected for both groups during the dual-task condition, as Table 10 indicates.

TABLE 10

SIGNIFICANCE OF DUAL-TASK CONDITION

Pearson's Correlations

\begin{tabular}{lllc}
\hline & & \multicolumn{3}{c}{ Pearson's $\mathrm{r}$} & $\mathrm{p}$ \\
\hline T2 Difficulty & - Accuracy level - Plain & 0.031 & 0.744 \\
T2 Difficulty & - Accuracy Level Green & -0.024 & 0.804 \\
T2 Difficulty & - Accuracy Level - Red & -0.033 & 0.727 \\
Accuracy level - Plain & - Accuracy Level Green & 0.925 & $* * *<.001$ \\
Accuracy level - Plain - Accuracy Level - Red & 0.917 & $* * *<.001$ \\
Accuracy Level Green - Accuracy Level - Red & $0.960 * * *<.001$ \\
\hline$* \mathrm{p}<.05, * * \mathrm{p}<.01, * * * \mathrm{p}<.001$ &
\end{tabular}

As the Table indicates, there was a clear correlation between levels of accuracy and the perceived task difficulty. Again, this underlines the cognitive trade-off between task complexity and accuracy. It appears that the cognitive load needed to manage the split attention needs of the task was achieved at the expense of accuracy, which again indicates that there is veracity in the trade-off and cognition hypothesis. In terms of how the accuracy was lost, the major area appeared to be in formulation, based on the stimulated recall comments. 
For the stimulated recall, this was an offline process designed to tap into the perceived use of cognitive processes as self-reported by the participants, using a stimulus from the task. The anticipation from both the trade-off hypothesis and the cognition hypothesis was that the more complex tasks would lead to variations in the comments made at recall. From work by Malicka (2018), there was evidence that tasks should be sequenced from simple cognitive load to more complex as their proficiency increases. For example, one respondent indicated:

"In the town centre traffic problem task, I kept worrying about the time to do the task, and how to give the best solution. I kept second-guessing my decisions and this made me feel anxious about completing the task" (NS)

One of the NNS also indicated that time was a factor, but for different reasons, as the following comment indicates:

"I knew what I wanted to explain, but I couldn't find the word, I was thinking of a roundabout and kept coming up with other words because I was a bit stressed about being able to give the right answer, so I stumbled on my words". (NNS)

The first comment indicates an issue concerning conceptualizations, whilst the second appears to be a formulation problem. Other comments were similar, identifying issues with recalling a word for the NNS, and for the NS the most complex facet was to find the right solution, as illustrated by the following comments:

"I really couldn't remember the word because I was giving my attention to the problem itself, so I think I made some grammar mistakes" (NNS)

"I kept pausing because I was trying to make sure I got the flow of information right and I think I mixed up some words" (NS).

What this appears to indicate is that for NS, the conceptualization load may be greater, whilst for NNS it is the formulation that requires the greater effort and potentially causes the higher levels of anxiety identified. The findings from Malicka (2018) align with those of this work, that a continuum from simple to complex sequencing led to higher speech rate, accuracy, and structural complexity, suggesting that when designing TBL syllabi, the cognitive load element should be taken into account.

In terms of the qualitative responses during the stimulated recall phase, both groups of participants focused on explaining their hesitations, for example, considering time factors for completion, and re-evaluation of responses and accurate answers. In other words, there was a level of self-debate about the best way forward. These processes are common in EFL learners, but also present in NS, and this was evident in this study.

There was, moreover, an indication that self-debate and thinking aloud was particularly the case in relation to the problem-solving task. This suggests that assessing a problem requires a level of conceptualization before solutions can be found. What this confirms is that a greater level of working memory load and cognitive effort is required as the task needs to be resolved in stages. In essence, where a complex task is required to be completed, there is a need for a greater level of conceptualization, which increases the overall cognitive load.

In terms of formulation, there were issues with lexical recall, and self-questioning about the right word or phrase to use, particularly during the narrative task. Again, this suggests that during the tasks, the participants were focused on the task completion but that they had to expend greater effort and thus cognitive load to ensure that they provided the correct answers which are in line with recent work by Park and Lee (2018).

In terms of variation between the NS and NNS, there was no significant variation in the time estimations required to complete the tasks, but a small disparity in the assessment of the effort expended, particularly in relation to formulations, rather than conceptualizations. This suggests that when tasks are in L2, there is an additional effort required for formulations, due to the unfamiliarity of the L2. This would however need further investigation in future research.

\section{DISCUSSION}

In the previous section, the statistical results were reported in detail. In this section, the findings are reported and discussed in relation to the research questions. The focus of this study was to determine how manipulation of the complexity of a task affected the cognitive processes of NS and NNS users of English. The aim was to identify whether there was an optimal sequencing of tasks that could be introduced into the classroom for improvement in the results of EFL learners. The findings have suggested that there is veracity in the trade-off and cognition hypotheses and the relationship between the complexity of task on cognitive load and working memory (Skehan, 2011; Robinson, 2001). In addition, there is a level of self-debate and thinking aloud which increases in line with the complexity of a task, particularly those where there is a dual load requirement, such as in the mapping exercise.

Concerning the effect of manipulating task complexity for narrative tasks, we found that there is a significant impact on speech production processes, with fluency, and accuracy diminishing in direct correlation with increases in complexity (RQ1). However, the impact is less than that seen for other more complex tasks, as noted by (Shehadeh, 2005; Ong \& Zhang, 2013).

With respect to the second research question, there was a clear reduction in accuracy and an increase in cognitive load. Responses from the participants suggested that the focus was on task completion rather than accuracy and fluency which had a negative effect on perceptions of task completion. In line with Cierniak et al, (2009) the split-attention aspect of this task was a factor in reducing accuracy and fluency.

The third research question identified that in problem-solving tasks, as the complexity of the problem to be resolved increased, there was a subsequent reduction in the ability to deliver fluent, accurate responses. This indicates that the 
increase in cognitive load impacted directly on conceptualisation and formulation ability which aligns with work by Levkina, \& Gilabert, (2012).

The results have suggested that there is a need to commence the TBL process with simple tasks that require less cognitive load and mental effort, and gradually increase this over time which aligns with Malicka, (2018) and Bowles (2018). However, there is also an indication that when learners complete one simple task (the narrative for example), they are more receptive subsequently attempting a more complex task (mapping exercise). What is less clear is whether the increased mental effort can be manipulated through changing tasks after encouraging self-reflection and evaluation of errors of the previous task. Furthermore, consideration is required regarding any potential impact from the interaction on cognitive load. From a pedagogical perspective, there are indications that a focus on different complexity levels may lead to improved mental effort and motivation in a task-based syllabus. However, the complexity should increase gradually as students become more familiar with the cognitive loads and the mental effort required to solve tasks.

It had been anticipated that in line with Levkina and Gilabert, (2012), Robinson (2001), Sasayama and Izumi (2012) that there would be a decrease in fluency when tasks had more elements, but an increase in linguistic complexity and accuracy. Despite these views, the results showed no impact on fluency when tasks had a greater level of complexity and elements. In addition, there was partial confirmation of the cognition hypothesis because an increase in task elements did lead to fewer morphosyntactic errors per AS-unit, longer clauses, and more lexical diversity.

Furthermore, and using the example of Levkina (2008), Levkina and Gilabert (2012), and Sasayam and Izumi (2012) learners were only given five minutes for strategic planning. There is a potential that if participants had been allowed additional time for planning, the effect of the pre-task stage may have been more evident. In line with Mehnert (1998) there is a potential that longer planning time (for example, ten minutes), resulted in improvement in fluency, lexical density, accuracy, and syntactic complexity). This suggests that the greater the planning time, the less the trade-off effect is seen. In other words, there were no trade-off effects because the participants had the time to prioritize form, focus their attention on formulation, and used the planning for this purpose rather than organising ideas. This means that there was a focus on conceptualization of the message.

Given that the approaches taken in this work were based on identifying variations in cognitive load and attempting to further empirically test the trade-off and cognition hypothesis in the context of TBL, the results have provided some interesting insights. The suggestion is that whilst the cognition and trade-off hypotheses frameworks retain validity new frameworks which take into account the impact on specific speech production processes may be necessary to enable application in the development of grading and scheduling tasks in a syllabus. The initial findings of this work, therefore, indicate that more work is necessary in order to be able to develop this new framework. At this stage, however, it may be the case that complexity has a strong impact on the ability to conceptualize, and formulate speech in L2, which means that developing and setting of tests need to take into account the factor of complexity before they are included in a given syllabus. These findings align with previous studies into the effect of complexity (Abdollahzadeh et al. 2012; Cierniak et al, 2009), but also point to a need for further investigation.

\section{CONCLUSION, LimitATIONS AND Future RESEARCH}

The aim of the current work was to examine what effect task complexity had on speech production processes for NS and NNS. It is important to identify the value of understanding the cognitive load, mental effort, and impact on working memory of the complexity of tasks. This work aimed to move forward from these works and identify the variations that may exist in terms of cognitive load and its impact on speech production processes such as conceptualization and formulation (lexical, semantic, syntactic). The goal was to be able to identify how to grade and sequence tasks of varying complexity for the best outcomes for L2 learners. By comparing the outcomes for NS and NNS, it was identified that there was no significant variation. Thus, further investigation is necessary in regards to the process of reformulation and lexical recall, which were cited by some NNS as the reasons for their hesitations and the extended time required to complete a task. Furthermore, future research should give greater emphasis to assessment of overall fluency and accuracy in the task conditions and compare these for NNS and NS. It is further recognized that a limitation of this work is the small sample, and larger cohorts need to be examined to verify the overall work and its findings.

In addition, one of the key facets of the TBL approach is the interaction between peers and other interlocutors. The effects of the interaction were not assessed in this work as the individual participants predominantly undertook the tests on their own, with some small level of discussion for the narrative and problem-solving tests. Future research should consider investigating and comparing individual rankings on task load/complexity/cognitive impact with the effect of group dynamics so that a clear indication of the effect of interaction can be assessed.

Furthermore, it would be of benefit to examine if there are variations in cognitive load during interaction with NNS and NS or NNS/NNS groups and what effect this has on the trade-off between cognitive load and complexity in different students. Given that NS is familiar with language, there is a potential that the cognitive load on narrative/problem-solving tasks would be less than that seen in NNS. In sum, for the cognitive impacts of task manipulation, this study has identified the importance of correctly sequencing and grading tasks in terms of complexity level, based on the perceived cognitive load, more needs to be done. 


\section{REFERENCES}

[1] Abdollahzadeh, S., \& Fard Kashani, A. (2012). The effect of task complexity on EFL learners' narrative writing task performance. Journal of English Language Teaching and Learning, 3(8), pp.1-28

[2] Abeysekera, L., \& Dawson, P. (2015). Motivation and cognitive load in the flipped classroom: definition, rationale and a call for research. Higher education research \& development, 34(1), pp.1-14.

[3] Archard, M., \& Niemeier, S. (2004). Cognitive Linguistics, Language Acquisition, and Pedagogy. Berlin: Mouton de Guyter

[4] Baddeley, A. (2003). Working memory: looking back and looking forward. Nature reviews neuroscience, 4(10), pp.829-839.

[5] Bowles, M.A. (2018). Introspective Verbal Reports: Think-Alouds and Stimulated Recall. In The Palgrave Handbook of Applied Linguistics Research Methodology (pp. 339-357). Palgrave Macmillan, London.

[6] Breen, M. P. (1987). Learner Contributions to task design. In C.N. Candlin and D. Murphy (eds.). Lunca.srer Practical Papers in English Language Education. Vol. 7. Language Learning Tasks, 23-46. Englewood Cliffs, NJ: Prentice Hall.

[7] Cierniak, G., Scheiter, K., \& Gerjets, P. (2009). Explaining the split-attention effect: Is the reduction of extraneous cognitive load accompanied by an increase in germane cognitive load? Computers in Human Behavior, 25(2), pp.315-324.

[8] Doughty, C., \& Pica, T. (1986). Information gap tasks: An aid to SLA? . TESOL Quarterly, 20(2), pp. 305-325

[9] Ellis, R. (2003). Task Based Language Teaching and Learning. Oxford: Oxford University Press.

[10] Ellis, R. (2006). The methodology of task-based teaching. Asian EFL journal, 8(3), pp.19-45.

[11] Farrokhi, F., \& Sattarpour, S. (2017). Different Task Complexity Factors and Cognitive Individual Differences: The Effects on EFL Writers' Performance Applied Research on English Language, 6(3), pp.387-410.

[12] Gass, S., \& Mackey, A. (2007). Input, interaction, and output in second language acquisition. In B. VanPatten and J. Williams (Eds.), Theories in second language acquisition, pp. 175-200. Mahwah, NJ: Lawrence Erlbaum.

[13] Gilabert, R., Barón, J., \& Llanes, À. (2009). Manipulating cognitive complexity across task types and its impact on learners' interaction during oral performance. International Review of Applied Linguistics in Language Teaching, 47(3-4), pp. 367-395.

[14] Gilabert, R. (2007). Effects of manipulating task complexity on self-repairs during L2 oral production. International Review of Applied Linguistics in Language Teaching, 45(3), pp.215-240.

[15] Haidet, P., Kubitz, K., \& McCormack, W.T. (2014). Analysis of the team-based learning literature: TBL comes of age. Journal on excellence in college teaching, 25(3-4), pp. 303-333.

[16] Harwood, N. (2010). English Language Teaching Materials. Cambridge: Cambridge University press

[17] Holmqvist, K., Nyström, M., Andersson, R., Dewhurst, R., Jarodzka, H., \& Van de Weijer, J. (2011). Eye tracking: A comprehensive guide to methods and measures. Oxford, UK: Oxford University Press.

[18] Ishikawa, T. (Ed.) (2007). The effect of manipulating task complexity along the [+/-Here-and-Now] dimension on L2 written narrative discourse. Clevedon, Avon: Multilingual Matters.

[19] Jong, Y.O. (2009). An investigation into the benefits of collaborative writing for the development of EFL children's communication skills: A reflective report of a teacher researcher (Doctoral dissertation, University of Warwick).

[20] Kalyuga, S. (2011). Cognitive load theory: How many types of load does it really need? Educational Psychology Review, 23(1), pp.1-19.

[21] Kormos, J. (2006). Speech production and second language acquisition. Mahwah, NJ: Lawrence Erlbaum Associates

[22] Kuiken, F., \& Vedder, I. (2007). The influence of complexity in monologic versus dialogic tasks in Dutch L2. International Review of Applied Linguistics, 45(3), pp. 241-259.

[23] Lee, J. (2019). Time-on-task as a Measure of Cognitive Load in TBLT. Journal of Asia TEFL, 16(3), pp. 958-969.

[24] Levkina, M. (2008). The effects of increasing cognitive task complexity along [+/-planning Time] and [+/-few Elements] on L2 oral production. Unpublished Master dissertation. University of Barcelona

[25] Levkina, M., \& Gilabert, R. (2012). The effects of cognitive task complexity on L2 oral production. Dimensions of L2 performance and proficiency investigating complexity, accuracy, and fluency in SLA, pp.171-198.

[26] Liao, P.C. (2019). Understanding EFL Learner Agency in Collaborative Activities: A Case Study in a Taiwanese English Course. The Journal of Asia TEFL. 16(3), pp. 768-782.

[27] Littlewood, W. (2004). The task-based approach: Some questions and suggestions. ELT journal, 58(4), pp. 319-326.

[28] Mackey, A. (2007). Interaction as practice. In R. DeKeyser (ed.), Practice in a second language: Perspectives from applied linguistics and cognitive psychology. pp. 85-110. Cambridge: Cambridge University Press.

[29] Malicka, A., 2018. The role of task sequencing in fluency, accuracy, and complexity: Investigating the SSARC model of pedagogic task sequencing. Language Teaching Research, p.1362168818813668.

[30] Malicka, A., \& Levkina, M. (2012). Measuring task complexity: Does EFL proficiency matter? Task-based language teaching in foreign language contexts: Research and implementation, pp. 43-66. Amsterdam: John Benjamins

[31] Mehnert, U. (1998). The effects of different lengths of time for planning on second language performance. Studies in second language acquisition, 20, pp.83-108.

[32] Moattarian, A., Tahririan, M.H., \& Alibabae, A. (2019). Task Complexity Manipulation and EFL learners' interactions in the process of collaborative pre-planning. Applied Research on English Language, 8(1), pp.51-78.

[33] Nation, I. S. P., \& Newton, J. (2009). Teaching ESL/EFL speaking and listening. New York: Routledge

[34] Nation, I.S.P. (2011). Second language speaking. In E. Hinkel (Ed.), Handbook of research in second language teaching and learning (pp.445-454). New York: Routledge.

[35] Ong, J., \& Zhang, L.J. (2013). Effects of the manipulation of cognitive processes on EFL writers' text quality. TESOL quarterly, 47(2), pp.375-398.

[36] Ozverir, I., Osam, U.V., \& Herrington, J. (2017). Investigating the effects of authentic activities on foreign language learning: A design-based research approach. Journal of Educational Technology \& Society, 20(4), pp.261-274. 
[37] Park, H., \& Lee, H. (2018). The effects of task complexity on Korean adult EFL learners' summary writing. Modern English Education, 19(1), pp. 62-75.

[38] Pica, T. (2013). From input, output and comprehension to negotiation, evidence, and attention. An overview of theory and research on learner interaction and SLA. In M. P. Garcia Mayo, M. J. Gutierrez Magado, \& M. Martinez Adrian (ed.), Contemporary approaches to second language acquisition, (pp.49-79). Amsterdam, The Netherlands: John Benjamins.

[39] Prahbu, N. S. (1980). 'Reactions and predictions' [Special issue]. Bulletin 4(1). Bangalore: Regional Institute of English, South India

[40] Révész, A. (2011). Task complexity, focus on L2 constructions, and individual differences: A classroom-based study. The Modern Language Journal, 95, pp.162-181.

[41] Robinson, P. (2001). Task complexity, task difficulty, and task production: exploring interactions in a componential framework. Applied Linguistics, 22(1), pp. 27-57

[42] Robinson, P. (2003). The Cognition Hypothesis, task design and adult task-based language learning. Second Language Studies, 21(2), 45-107.

[43] Robinson, P. (2007). Task complexity, theory of mind, and intentional reasoning: Effects on speech production, interaction, uptake and perceptions of task difficulty. International Review of Applied Linguistics in Language Teaching, 45(3), pp. 195215

[44] Robinson, P. (2011). Task-Based Language Learning: A Review of Issues. Language Learning, 61, 1-36.

[45] Sasayama, S., \& Izumi, S. (2012). Effects of task complexity and pre-task planning on Japanese EFL learners' oral production. In Shehadeh, A., \& Combe, C. A. (eds.), Task-based language teaching in foreign language contexts. Research and implementation, pp. 23-42. Amsterdam: John Benjamins

[46] Schmidt, R. (Ed.) (2012). Attention, awareness, and individual differences in language learning. . Boston: MA: Mouton de Gruyter.

[47] Shajeri, E., \& Izadpanah, S. (2016). The impact of task complexity along single task dimension on Iranian EFL learners' writing production. Theory and Practice in Language Studies, 6(5), pp.935-945.

[48] Shehadeh, A. (2005). Task-based language learning and teaching: Theories and applications. In Teachers exploring tasks in English language teaching (pp. 13-30). Palgrave Macmillan, London.

[49] Shehadeh, A., \& Coombe, C.A. (eds) (2012). Task-based language teaching in foreign language contexts: Research and implementation, Amsterdam: John Benjamins.

[50] Skehan, P. (1996). A framework for the implementation of task-based instruction. Applied linguistics, 17(1), pp.38-62.

[51] Skehan, P. (1998). A cognitive approach to language learning. Oxford. Oxford University Press.

[52] Skehan, P. (2001). Tasks and language performance. In M. Bygate, P. Skehan, \& M. Swain (eds.), Researching pedagogic tasks: Second language learning, teaching, and testing, (pp. 167-185). London: Longman.

[53] Skehan, P., \& Foster, P. (Eds.). (2001). Cognition and tasks. Cambridge: Cambridge University Press.

[54] Swain, M. (1985). Communicative competence: Some rules of comprehensible input and comprehensible output in its development. In S. Gass \& C. Madden (Eds.), Input in second language acquisition (pp. 235-253). Rowley, MA: Newbury House.

[55] Van Avermaet, P., \& Gysen, S. (2006). From needs to tasks: Language learning needs in a task-based approach. Task-based language education: From theory to practice, 17, pp.46-61.

[56] Van Patten, B. (1990). Attending to form and content in the input. Studies in Second Language Acquistition, 12(3), pp. 287-301.

[57] Viriya, C. (2018). Using task-based learning with students of academic English. Arab World English Journal, 9(4), pp. 337-346.

[58] Willis, J. (1996). A flexible framework for task-based learning. London: Longman.

[59] Zhai, X., Dong, Y., Wang, S., Wang, L., \& Yuan, J. (2019). Exploring eye-tracking analyses of EFL learners' cognitive processing of reduced relative clause. Cluster Computing (3), pp.1-12.

Adnan Mukhrib is an assistant professor of Applied Linguistics and TESOL at Yanbu University college, Yanbu, Saudi Arabia. He completed a $\mathrm{PhD}$ in the areas of second language acquisition from the University of Bristol, UK, did an MA in Applied Linguistics and TESOL at Newcastle University, and his BA degree in English language and Linguistics from Umm AL- Qur'a University, Makkah, Saudi Arabia. He taught a variety of courses at Yanbu University College, including phonetics \& phonology, Introduction to Applied Linguistics, sociolinguistics, pragmatics, Linguistics and academic writing in Applied Linguistics department at Yanbu University College. More recently he worked as an EAP tutor at the University of Nottingham, and Southampton University in the UK, and also taught academic writing for undergraduate programs in Yanbu Industrial College, Yanbu, Saudi Arabia.

His research interests lie in the areas of second language acquisition. In particular, he conducts research on the roles of tasks, input, interaction and individual differences in $\mathrm{L} 2$ development. $\mathrm{He}$ is also interested in aspects of second language acquisition including fluency, pronunciation, accuracy and complexity of L2 speech production and comprehension, the cognitive processes underlying L2 learning. His current projects investigate the cognitive processes involved in second language writing and speaking, the role of output-based tasks in second language learning, and sources of difficulty in second language production. 